\title{
Fabricação de blocos cerâmicos de vedação pela incorporação com lodo de lavanderia industrial
}

\author{
(Production of ceramic sealing blocks with incorporation of \\ sludge from industrial laundry)
}

\author{
L. C. S. Herek, R. Bergamasco, C. R. G. Tavares \\ CTC - DEQ, Universidade Estadual de Maringá, Av. Colombo 5790, Zona 7, Maringá, PR 87020-900 \\ luciana_csh@hotmail.com
}

\begin{abstract}
Resumo
O resíduo sólido (lodo) gerado durante o tratamento de efluentes de lavanderias industriais foi utilizado na fabricação de blocos cerâmicos de vedação em escala real, nas proporções de 0 (referência) e $20 \%$ de lodo em relação à massa cerâmica. Após a queima, em escala industrial, estes blocos cerâmicos foram avaliados com relação aos ensaios de resistência mecânica e absorção de água. Os blocos cerâmicos de vedação fabricados com lodo de lavanderia apresentaram uma diminuição na resistência mecânica com relação aos blocos de referência. Já o teor de absorção de água aumentou ao se adicionar lodo de lavanderia na fabricação destes blocos. No entanto, os resultados mostraram que o lodo de lavanderia pode ser aproveitado para incorporação em massa cerâmica na fabricação de blocos cerâmicos de vedação até $20 \%$.
\end{abstract}

Palavras-chave: lodo de lavanderia, resistência mecânica, absorção de água, bloco cerâmico de vedação.

\begin{abstract}
The solid residue (sludge) generated in the treatment of effluents from industrial laundries was used for the full-scale production of ceramic sealing blocks, in the proportions of $0 \%$ (reference) and $20 \%$ with respect to the ceramic body. After firing in industrial scale, the mechanical strength and water absorption properties of the ceramic blocks were determined. The ceramic blocks produced with laundry sludge showed lower mechanical strength than the reference blocks. On the other hand, the amount of absorbed water increased when the sludge was added to the blocks. The results showed that the sludge from industrial laundries may be incorporated in the ceramic body, up to $20 \%$, for the production of ceramic sealing blocks.
\end{abstract}

Keywords: laundry sludge, mechanical strength, water absorption, ceramic sealing block.

\section{INTRODUÇÃO}

As estações de tratamento de efluentes de lavanderias industriais geram, durante o tratamento primário (físicoquímico) ou secundário (biológico), grande quantidade de resíduo sólido, o lodo. Este lodo, segundo a NBR 10.004/04 Resíduos Sólidos [1] é de classe IIA, ou seja, não inerte, pois possui constituintes solubilizados em concentrações superiores ao anexo $G$ da referida norma, e seu destino geralmente é o aterro industrial, mas é passível de aproveitamento. A construção civil vem sendo destaque para receber estes resíduos, seja na incorporação de produtos cerâmicos ou em cimento. A utilização da argila como agente solidificante no tratamento de resíduos, passou a ser investigada a partir da constatação de que os processos clássicos à base de cimento e cal, não eram eficientes no tratamento de resíduos com alto teor de materiais orgânicos [2].

A indústria da cerâmica vermelha é altamente promissora para absorver resíduos poluentes. Isto é decorrente principalmente do fato que as massas argilosas utilizadas são, por natureza, heterogêneas [3]. As massas argilosas são materiais poliminerálicos constituídos de argilominerais (materiais plásticos) e minerais não argilosos (não plásticos), com ampla variação mineralógica, física e química [4].

Os resíduos sólidos industriais vêm sendo aproveitados com o intuito de preservar o ambiente e gerar produtos com menor custo. Estudos recentes comprovam o uso de resíduos sólidos industriais, principalmente na indústria cerâmica: lodo de ETA em cerâmica argilosa [5], onde foram realizados ensaios mecânicos para uso na construção civil; uso de lodo têxtil incorporado em argila para reaproveitamento na construção civil [6]; caracterização de lodo de ETA para reaproveitamento em cerâmica vermelha, com bons resultados para esta aplicabilidade [3]; borra de petróleo [7]; borra de petróleo utilizando solo argiloso e bentonita [8], entre outros. A reutilização destes resíduos pode resolver, de um lado, o problema de descarte em área da estação de tratamento e, por outro lado, diminuir a quantidade de massa cerâmica consumida e, portanto, o custo da matéria-prima para a produção da cerâmica [5].

Este artigo teve por objetivo estudar o efeito da incorporação de lodo de lavanderia industrial em massa 
cerâmica para a fabricação de blocos cerâmicos de vedação em escala real, visando seu aproveitamento como material de construção civil.

\section{MATERIAIS E MÉTODOS}

Matérias primas: lodo gerado na fase de tratamento primário na ETE de uma lavanderia industrial situada na região de Maringá, $\mathrm{PR}$; massa cerâmica industrial constituída de uma mistura de argilas, proveniente da região de Japurá, PR, utilizada para o preparo de tijolos em geral e telhas, armazenada na Cerâmica Barra Bonita, Japurá, PR.

Fabricação dos blocos cerâmicos de vedação: os blocos cerâmicos foram fabricados nas dependências da Cerâmica Barra Bonita, Japurá, PR, em processo industrial nas proporções de 0 (referência) e $20 \%$ em peso de lodo em relação à massa cerâmica. Como o processo realizado em escala industrial requer uma grande quantidade de material, para a realização do ensaio foi utilizado um total de 1000 kg de material para cada ensaio. Para a realização de cada ensaio, os materiais, previamente secos e caracterizados [9] foram pesados, adicionados com trator esteira ao misturador/ triturador para homogeneização. Em seguida foram levados por esteiras rolantes até a maromba, onde eram umedecidos com água (adicionada automaticamente até obtenção da umidade suficiente para que passasse pelo processo de extrusão). Os blocos cerâmicos foram moldados com pastas consistentes pelo processo de extrusão, após passar pela câmara de vácuo para a retirada do ar presente na mistura. $\mathrm{O}$ corte foi realizado automaticamente quando os tijolos saiam da boquilha da extrusora e passavam pela esteira rolante. Após o corte, os blocos cerâmicos foram secos naturalmente em ambiente sem incidência de sol ou vento até o ponto de queima, para evitar o aparecimento de trincas. Após a secagem natural, os blocos cerâmicos foram queimados em fornos intermitentes tipo chama reversível (consiste em uma abóboda fechada e piso de tijolos perfurados de modo a permitir a passagem dos gases de combustão para os dutos de tiragem). Os blocos cerâmicos ficaram no interior deste forno por $24 \mathrm{~h}$ até $100{ }^{\circ} \mathrm{C}$, onde ocorre a retirada da água presente, e após foram queimados por três dias até atingirem em torno de $900{ }^{\circ} \mathrm{C}$ (sinterização). A temperatura do forno era aumentada a cada $24 \mathrm{~h}$.

Análise dos blocos cerâmicos de vedação: os blocos cerâmicos de vedação foram avaliados em relação a ensaios mecânicos e físicos: nos ensaios mecânicos, foram realizados testes de resistência à compressão de acordo com o método de ensaio [10], em prensa mecânica com capacidade máxima de 20 tf; os ensaios físicos foram realizados com relação à absorção de água, segundo método de ensaio [10].

\section{RESULTADOS E DISCUSSÃO}

\section{Resistência à compressão}

As Tabelas I e II apresentam os valores médios de ruptura obtidos para os blocos cerâmicos de vedação fabricados com 0 (referência) e $20 \%$ em peso de lodo, respectivamente. Os ensaios foram realizados com 10 blocos, apesar de a norma exigir apenas seis blocos, garantindo assim, uma maior precisão nos resultados.

Nas Tabelas I e II observa-se um decréscimo do valor obtido para a resistência à compressão para os blocos cerâmicos de vedação fabricados com a presença de lodo quando comparado aos blocos cerâmicos fabricados sem a incorporação deste lodo. Para os blocos cerâmicos fabricados somente com a mistura de massa cerâmica o valor da resistência foi de 4,6 $\mathrm{MPa}$, enquanto que para os blocos cerâmicos contendo $20 \%$ em peso de lodo foi de $3,7 \mathrm{MPa}$, ou seja, houve uma diminuição em torno de $20 \%$ do valor da resistência quando foi incorporado lodo na composição dos blocos cerâmicos. Os blocos cerâmicos fabricados com lodo de lavanderia são em torno de $10 \%$ mais leves que os blocos cerâmicos comuns, fato comprovado experimentalmente pela diferença de peso entre eles. Provavelmente este fato contribui para esta diminuição na resistência à compressão dos blocos que contém lodo, pois o ensaio de absorção comprova um aumento do teor de água nos blocos. Com

Tabela I - Valores de resistência obtidos para blocos cerâmicos de vedação fabricados sem lodo (referência).

[Table I - Strength values obtained for the reference ceramic sealing blocks (without sludge).]

\begin{tabular}{ccccccc}
\hline $\begin{array}{c}\text { Blocos } \\
\text { Cerâmicos }\end{array}$ & $\begin{array}{c}\mathrm{C} \\
(\mathrm{cm})\end{array}$ & $\begin{array}{c}\mathrm{L} \\
(\mathrm{cm})\end{array}$ & $\begin{array}{c}\mathrm{H} \\
(\mathrm{cm})\end{array}$ & $\begin{array}{c}\text { Área bruta } \\
\left(\mathrm{cm}^{2}\right)\end{array}$ & $\begin{array}{c}\text { Carga } \\
(\mathrm{Kgf})\end{array}$ & $\begin{array}{c}\mathrm{R} \\
(\mathrm{MPa})\end{array}$ \\
\hline 1 & 20,6 & 10,1 & 14,8 & 208,06 & 99 & 4,843891 \\
2 & 20,6 & 9,9 & 14,9 & 203,94 & 96 & 4,791998 \\
3 & 20,5 & 10 & 14,8 & 205 & 94 & 4,667902 \\
4 & 20,7 & 10,1 & 15 & 209,07 & 98 & 4,771799 \\
5 & 20,3 & 10,1 & 15 & 205,03 & 96 & 4,766522 \\
6 & 20,4 & 10 & 14,9 & 204 & 97 & 4,84049 \\
7 & 20,5 & 10,2 & 14,8 & 209,1 & 90 & 4,381636 \\
8 & 20,2 & 10,1 & 15 & 204,02 & 89 & 4,440839 \\
9 & 20,3 & 10 & 14,9 & 203 & 87 & 4,362857 \\
10 & 20 & 10,1 & 14,8 & 202 & 86 & 4,334059 \\
Média & 20,41 & 10,06 & 14,89 & 205,322 & 93,2 & 4,62 \\
\hline
\end{tabular}


Tabela II - Valores de resistência obtidos para blocos cerâmicos de vedação fabricados com $20 \%$ em peso de lodo.

[Table II - Strength values obtained for the ceramic sealing blocks with 20 wt.\% sludge.]

\begin{tabular}{cccccccc}
\hline $\begin{array}{c}\text { Blocos } \\
\text { Cerâmicos }\end{array}$ & $\begin{array}{c}\mathrm{C} \\
(\mathrm{cm})\end{array}$ & $\begin{array}{c}\mathrm{L} \\
(\mathrm{cm})\end{array}$ & $\begin{array}{c}\mathrm{H} \\
(\mathrm{cm})\end{array}$ & $\begin{array}{c}\text { Área bruta } \\
\left(\mathrm{cm}^{2}\right)\end{array}$ & $\begin{array}{c}\text { Deformação } \\
\text { do Aro }\end{array}$ & $\begin{array}{c}\text { Carga } \\
(\mathrm{Kgf})\end{array}$ & $\begin{array}{c}\mathrm{R} \\
(\mathrm{MPa})\end{array}$ \\
\hline 1 & 18,7 & 9,2 & 14 & 172,04 & 44 & 45,05515 & 2,67 \\
2 & 18,9 & 9,3 & 14 & 175,77 & 30 & 31,13076 & 1,80 \\
3 & 18,8 & 9,4 & 14,1 & 176,72 & 80 & 80,86073 & 4,66 \\
4 & 18,6 & 9,2 & 14 & 171,12 & 72 & 72,90393 & 4,34 \\
5 & 18,7 & 9,3 & 14 & 173,91 & 64 & 64,94714 & 3,80 \\
6 & 18,9 & 9,2 & 13,9 & 173,88 & 84 & 84,83912 & 4,97 \\
7 & 18,5 & 9,3 & 14 & 172,05 & 76 & 76,88233 & 4,55 \\
8 & 18,6 & 9,2 & 13,7 & 171,12 & 82 & 82,84993 & 4,93 \\
9 & 18,9 & 9,3 & 14 & 175,77 & 38 & 39,08755 & 2,26 \\
10 & 18,6 & 9,3 & 14,2 & 172,98 & 56 & 56,99034 & 3,35 \\
Média & 18,72 & 9,27 & 13,99 & 173,536 & 62,6 & 63,5547 & 3,73 \\
\hline
\end{tabular}

a incorporação de borra oleosa em massa argilosa para a fabricação de blocos de vedação com relação aos blocos fabricados sem incorporação de borra de petróleo também já foi observado um comportamento linear decrescente [11]. A diminuição da resistência à compressão chegou a $31,5 \%$ para blocos contendo $20 \%$ de borra incorporada em relação à massa. Os autores devem esta diminuição na resistência a fatores não controlados no processo de fabricação, como umidificação, secagem, temperatura e tempo de queima. Apesar da diminuição do valor apresentado para o ensaio de resistência quando se aumenta o teor de lodo incorporado em massa cerâmica, os valores encontram-se dentro dos valores estabelecidos para blocos cerâmicos de vedação (NBR 15.270-3/05)[10], com valor mínimo de 1,5 MPa.

\section{Absorção de água}

As Tabelas III e IV apresentam os valores médios de absorção de água obtidos para os blocos cerâmicos fabricados sem (referência) e $20 \%$ em peso de lodo, respectivamente.

O ensaio de absorção de água foi realizado com o objetivo de verificar a porcentagem de água absorvida no período de $24 \mathrm{~h}$ à temperatura ambiente, pois quanto maior a quantidade de água absorvida maior será a porosidade dos blocos. No ensaio de absorção de água foi observado um aumento do teor de água nos blocos contendo lodo de lavanderia em relação aos blocos de referência. Quando se adicionou 20\% em peso de lodo à massa cerâmica houve um aumento de $55 \%$ na absorção de água com relação aos blocos cerâmicos fabricados sem a incorporação de lodo. Este aumento provavelmente também é devido ao fato de o lodo ser leve, absorvendo uma quantidade maior de líquidos, aumentado sua porosidade. A realização do ensaio de absorção de água em blocos cerâmicos de vedação fabricados com incorporação de borra oleosa em massa cerâmica mostrou um incremento da ordem de $24 \%$ na capacidade de absorção de água para blocos contendo $24 \%$ de borra incorporada com relação aos blocos de referência [11]. Apesar de a absorção de água ter aumentado com o aumento da adição de lodo
Tabela III - Valores de absorção de água obtidos para blocos cerâmicos de vedação fabricados sem lodo (referência). [Table III - Water absorption values obtained for the reference ceramic sealing blocks (0 wt.\% sludge).]

\begin{tabular}{cccc}
\hline $\begin{array}{c}\text { Blocos } \\
\text { Cerâmicos }\end{array}$ & $\begin{array}{c}\text { Massa seca } \\
(\mathrm{g})\end{array}$ & $\begin{array}{c}\text { Massa úmida } \\
(\mathrm{g})\end{array}$ & $\begin{array}{c}\text { AA } \\
(\%)\end{array}$ \\
\hline 1 & 2300 & 2600 & 9,80 \\
2 & 2300 & 2700 & 10,40 \\
3 & 2300 & 2600 & 10,32 \\
4 & 2300 & 2700 & 9,28 \\
5 & 2300 & 2700 & 9,87 \\
6 & 2300 & 2700 & 10,28 \\
7 & 2300 & 2700 & 10,23 \\
8 & 2300 & 2700 & 10,23 \\
9 & 2300 & 2700 & 10,45 \\
10 & 2300 & 2600 & 10,10 \\
Média & 2300 & 2670 & 10,10 \\
\hline
\end{tabular}

Tabela IV - Valores de absorção de água obtidos para blocos cerâmicos de vedação fabricados com $20 \%$ em peso de lodo. [Table IV - Water absorption values obtained for the ceramic sealing blocks with $20 \mathrm{wt} \% \%$ sludge.]

\begin{tabular}{cccc}
\hline $\begin{array}{c}\text { Blocos } \\
\text { Cerâmicos }\end{array}$ & $\begin{array}{c}\text { Massa seca } \\
(\mathrm{g})\end{array}$ & $\begin{array}{c}\text { Massa úmida } \\
(\mathrm{g})\end{array}$ & $\begin{array}{c}\text { AA } \\
(\%)\end{array}$ \\
\hline 1 & 1852,95 & 2140,02 & 15,49 \\
2 & 1848,85 & 2151,73 & 16,38 \\
3 & 1778,53 & 2056,87 & 15,65 \\
4 & 1784,42 & 2077,39 & 16,42 \\
5 & 1787,88 & 2073,88 & 16,00 \\
6 & 1945,07 & 2239,13 & 15,12 \\
7 & 1877,56 & 2169,11 & 15,53 \\
8 & 1789,47 & 2073,78 & 15,89 \\
9 & 1845,1 & 2136,43 & 15,79 \\
10 & 1858,35 & 2138,53 & 15,08 \\
Média & 1836,818 & 2125,687 & 15,73 \\
\hline
\end{tabular}


à massa cerâmica para a fabricação dos blocos cerâmicos, com $20 \%$ em peso de lodo ainda obtiveram-se valores de absorção dentro daqueles estabelecidos pela NBR 15270$3 / 2005$ [10], entre 8 a $22 \%$.

\section{CONCLUSÕES}

Os ensaios realizados nos blocos cerâmicos de vedação por meio da incorporação de lodo de lavanderia com teores de 0 (referência) e $20 \%$ em peso comprovam que a resistência é inversamente proporcional ao teor de lodo incorporado, enquanto a absorção de água é diretamente proporcional ao teor de lodo incorporado. Constatou-se que um teor de até $20 \%$ em peso de lodo em massa cerâmica, as propriedades mecânicas dos blocos cerâmicos após a queima sofrem alterações. Contudo os valores obtidos para os ensaios de resistência e de absorção estão dentro dos valores normativos para blocos cerâmicos de vedação (NBR 15.270-3/05). A fabricação de blocos cerâmicos com incorporação de lodo de lavanderia é benéfica principalmente para os geradores do lodo, pois o custo com o transporte do resíduo até aterros industriais é alto. Ensaios de lixiviação e de solubilização devem ser realizados nos blocos cerâmicos para comprovar a viabilidade de seu uso na construção civil, sem causar danos ao ambiente.

\section{REFERÊNCIAS}

[1] NBR 10.004 - Resíduos Sólidos. Classificação, Rio de Janeiro, RJ (2004).

[2] C. M. F. Vieira, C. A. C. M. Dias, A. V. Mothé, R. Sánchez, S. N. Monteiro, Cerâmica 53 (2007) 381.

[3] E. M. S. Oliveira, S. Q. Machado, J. N. F. Holanda, Cerâmica 50 (2004) 337.

[4] R. R. Menezes, H. S. Ferreira, G. de A Neves, H. C. Ferreira, Cerâmica 49 (2003) 127.

[5] I. C. C. Paixão, H. N. Yoshimura, D. C. R. Espinosa, J. A. S. Tenório, Cerâmica 54 (2008) 63.

[6] A. H. Moreira, R. M. Oliveira, P. D. S. Lima, Cerâmica 47 (2001) 158.

[7] R. S. Santos, G. P. Souza, J. N. F. Holanda, Cerâmica 48 (2002) 115.

[8] C. M. F. Vieira, S. N. Monteiro, Matéria 11 (2006) 217.

[9] L. C. S. Herek, R. Bergamasco, C. R. G. Tavares, R. C. Friozi, E. N. J. Júnior, Anais do XVII Congresso Brasileiro de Engenharia Química, Recife, PE (2008) 316.

[10] NBR 15.270-3/05 - Componentes Cerâmicos. Parte 3: Blocos Cerâmicos para Alvenaria Estrutural e de Vedação Métodos de Ensaio (2005).

[11] M. R. F. V. Alves, F. S. R. Holanda, Cerâmica Industrial 10 (2005) 41.

(Rec. 13/08/2009, Ac. 27/03/2010) 